\title{
TINGKAT PENGETAHUAN MENGENAI KESEHATAN REPRODUKSI PADA REMAJA LAKI-LAKI DI SMP NEGERI KOTA JAMBI
}

\author{
Lisa Anita Sari ${ }^{1}$, Meinarisa ${ }^{2}$, Muh Taufikri ${ }^{3}$ \\ ${ }^{1,3}$ Prodi Keperawatan, STIKes Harapan Ibu Jambi \\ ${ }^{2}$ Fakultas Kedokteran dan Ilmu Kesehatan, Prodi Keperawatan, Universitas Jambi \\ Email: ${ }^{1}$ lisaanitasari10@gmail.com
}

\begin{abstract}
ABSTRAK
Remaja berada pada tahap perubahan darimasa kanak-kanak menuju dewasaan yang ditunjukkan dengan perubahan fisik, emosional dan psikologis, yang mengakibatkan remaja menjadi relative fluktuatif bila dibandingkan dengan tahap perkembangan lainnya. Pengetahuan tentang kesehatan reproduksi sanga tpenting bagi remaja, guna meningkatkan perilaku kesehatan, menghindari seks bebas, dan mengurangi angka penularan penyakit menular seksual. Adapun tujuan dari dilakukannya studi ini adalah untuk mengidentifikasi tingkat pengetahuan remaja laki-laki tentang kesehatan reproduksi di SMP di Kota Jambi Tahun 2020. Desain penelitian menggunakan penelitian deskriptif kuantitatif yang dilaksanakan di SMP Negeri 4, 6 dan 17 Kota Jambi pada periode Juni sampai Agustus 2020. Jumlah total sampling 220 responden yang dipilih secara acak dengan metode simple random sampling. Instrumen yang dipaka imerupakan kuesioner yang telah dimodifikasi sebelumnya oleh peneliti serta valid dan reliabel. Analisis univariat digunakan sebagai analisis statistik dalam penelitian ini. Menurut hasil yang telah didapatkan, diketahui bahwa secara statistic remaja di SMP 4, 6 dan 17 di Kota Jambi memiliki pengetahuan yang tinggi tentang kesehatan reproduksi $(55,9 \%)$. Upaya yang bias dilaksanakan oleh tenaga kesehatan atau perawat adalah dengan memberikan pendidikan secara berkala kepada remaja tentang kesehatan reproduksi, sehingga remaja memperoleh pemahaman yang benar dan terhindar dari pengaruh buruk penyimpangan dalam kesehatan reproduksi.
\end{abstract}

Kata Kunci: Pengetahuan, Kesehatan Reproduksi, Remaja.

\section{ABSTRACT}

Adolescenceas a phase of transition from children to adult marked by physical, emotional and psychological changes, which cause adolescence to be relatively volatile compared to other developmental periods. Knowledge about health reproductive is very important for adolescent, in order to improve health behavior, avoid casual sex, and reduce the number of sexually transmitted infections. The aims of this research study was to identify the level of knowledge of male adolescents about health reproductive at Junior High School at Kota Jambi in 2020. The research design was used descriptive quantitative study which conducted at Junior High Schoolof 4, 6 and 17 at Jambi City from June to August 2020. The total sampling amount of 220 respondents who randomly selected by using simple random sampling method. The instrument was used the questionnaire that was modified by the researcher and also valid and reliable. Univariate analysis was used as analysis statistic in this study. Basedon the research that has been done, it was showed that statistically adolescents at Junior High School of 4, 6 and 17 at Jambi City had high level of knowledge on health reproductive (55.9\%). The efforts that can be made by health workers or nurses are to provide regular education to adolescents about health reproductive, so the adolescents get the correct understanding and avoid adverse effects of irregularities in health reproductive.

Keywords: Knowledge, Health Reproductive, Adolescent.

\section{PENDAHULUAN}

Remaja merupakan sebuah periode dimana seseorang menjadi berkembang dari mulai pertama kali menunjukkan adanya tanda seksual sekunder hingga ia berada pada masa kematangan seksual, menjalani perkembangan secara psikologis dan pola identitas bermula dari anak-anak menuju dewasa, serta mengalami masa peralihan dari yang bersifat tergantung secara penuh terhadap sosial-ekonomi menuju situasi yang cenderung lebih baik (1).

Remaja mengalami pertumbuhan dan perkembangan pesat pada aspek fisik, 
psikologis dan juga intelektual. Beberapa karakteristik remaja yaitu mempunyai keingintahuan yang besar, suka berpetualang, menyukai tantangan, serta berani mengambil resiko sebagai konsekuensi atas perbuatan yang dilakukan tanpa memiliki pertimbangan yang matang (2).

Kesehatan Reproduksi pada Remaja (KRR) adalah bagian yang berkesinambungan dari suatu program kesehatan dan keluarga berencana yang ada di Indonesia, dimana kegiatan ini bertujuan untuk meningkatkan pengetahuan dan keterampilan remaja mengenai pentingnya kesehatan pada reproduksi dan perilaku hidup yang sehat serta menyediakan layanan kesehatan yang berkualitas baik pada remaja (3).

Masalah kesehatan reproduksi yang sering kali muncul berupa penyakit pada bagian kelamin seperti iritasi pada bagian genital, timbulnya alergi, radang atau infeksi pada saluran kencing (4). Permasalahan yang sering kali muncul pada masa remaja pada periode permulaan matangnya organ reproduksi yaitu perilaku beresiko yang mengarah pada seks bebas (free sex) yang berupa kehamilan diluar pernikahan yang terjadi pada usia sekolah, dan tertularnya penyakit menular seksual, salah satunya HIV/AIDS (5).

Remaja laki-laki dan perempuan memiliki kerentanan yang sama terhadap masalah kesehatan yang berkaitan dengan organ reproduksi. Namun kebiasaan seperti merokok dan konsumsi minuman keras sering kali terjadi pada remaja laki-laki yang kedepannya tentu akan berpengaruh pada kesuburan organ reproduksi di kemudian hari (6).

Cara memelihara organ reproduksi secara umum baik bagi laki-laki yaitu tidak menggunakan celana yang ketat yang bias mempengaruhi suhu testis, sehingga menghambat produksi sperma dan melakukan khitan untuk mencegah terjadinya penumpukan kotoran atau smegma (cairan yang berada dalam kelenjar sekitar alat kelamin dan sisa air kencing) sehingga alat kelamin menjadi bersih, maka dari itu pengetahuan sangat penting terhadap kesehatan reproduksi (4).

Pada organ reproduksi yang kebersihannya tidak terjaga dengan baik akan sangat rentan terkena penyakit yang dikarenakan oleh fungi dan bakteri. Penyakit pada organ reproduksi juga dapat ditimbulkan dari pola hidup yang kurang sehat pada masa remaja berupa kebiasaan merokok, konsumsi alkohol yang tentunya berakibat pada impotensi. Adapun penyakit yang timbul pada organ reproduksi tidak selalu muncul pada saat ini, namun biasa muncul ditahun mendatang yang tentunya akan dapat mempengaruhi pada fertilitas pria di masa reproduksi, sehingga dibutuhkan pengetahuan yang baik (6).

Perilaku yang didasari pada pengetahuan akan berakibat lebih baik jika dibandingkan dengan perilaku yang tidak didasarkan pada pengetahuan (7). Dengan memiliki pengetahuan yang baik dapat membuat sikap serta perilaku para remaja dalam mempertahankan kesehatan reproduksi menjadi positif, sehingga remaja tersebut dapat terhindar dari terjangkitnya penyakit menular seksual, kehamilan remaja diluar pernikahan, penyakit organ reproduksi, serta terganggunya pendidikan dan pekerjaan. Salah satu penyebab penyimpangan perilaku seksual pra nikah remaja yaitu kurangnya dukungan orang tua (4).

Minimnya pengetahuan tentang proses reproduksi, pentingnya memelihara organ reproduksi agar selalu terjaga kebersihannya dan dampak dari perilaku yang kurang bertanggungjawab dapat menyebabkan beberapa dari remaja mengalami berbagai masalah yang berkaitan dengan organ reproduksi (8).

Pengetahuan dan persepsi yang kurang tepat mengenai perbedaan kelamin dan kesehatan pada organ reproduksi dapat mengakibatkan remaja menjadi berperilaku beresiko terhadap kesehatan reproduksi sehingga sangat penting untuk melihat pengetahuan remaja mengenai pentingnya kesehatan reproduksi (3).

Di dalam fase perkembangan pada remaja terjadi perubahan yang signifikan baik perubahan secara biologis serta perubahan psikologis (perempuan mengalami menstruasi dan laki-laki mengalami mimpi basah) yang mengakibatkan pada periode remaja menjadi relative bergejolak bila dibandingkan dengan periode perkembangan yang lainnya, sehingga mengakibatkan periode remaja menjadi urgensi untuk diprioritaskan. 
Berdasarkan hasil survey pendahuluan berupa wawancara singkat, didapatkan bahwa dari 10 remaja laki-laki, 6 diantaranya tidak mengetahui tentang pentingnya kesehatan reproduksi seperti hormon yang dihasilkan oleh laki-laki, 7 diantaranya mengerti tentang perubahan fisik berupa timbulnya jakun dan perubahan suara. Adanya permasalahan yang timbul pada remaja laki-laki tersebut, maka peneliti berkeinginan untuk melaksanakan studi mengenai bagaimana tingkat pengetahuan remaja laki-laki tentang kesehatan reproduksi.

Adapun tujuan dari dilakukannya studi ini yaitu untuk mengetahui tingkat pengetahuan remaja laki-laki tentang kesehatan reproduksi di SMP Negeri Kota Jambi Tahun 2020. Manfaat penelitian ini secara akademik yaitu sebagai informasi tentang pentingnya pengetahuan remaja lakilaki mengenai kesehatan reproduksi. Sedangkan manfaat praktis dari studi ini yaitu untuk memberikan gambaran kepada tenaga kesehatan maupun masyarakat umum untuk selalu memperhatikan kesehatan remaja, terutama pada bagian reproduksi demi menunjang kualitas hidup mereka dikemudian hari agar menjadi lebih baik.

\section{METODE}

Penelitian ini berupa descriptive analytic yang bertujuan untuk mengetahui tingkat pengetahuan remaja laki-laki di SMP Negeri Kota Jambi mengenai kesehatan reproduksi. Seluruh siswa SMP 4, 6 dan 17 laki-laki yang berada di kelas 7 yang berjumlah 512 siswa adalah sebagai populasi. Siswa kelas 7 dipilih sebagai responden dalam penelitian ini dikarenakan pada masa awal sekolah menengah pertama, responden berada pada masa awal transisi dari kanak-kanak menuju remaja awal. Sampel dalam penelitian ini menggunakan rumus lameshow, dengan presisi 5\% dan proporsi kejadian 0,5, sehingga didapatkan sampel sebanyak 220 responden yang diambil secara simple random sampling, dimana metode pengambilan sampel dilakukan secara acak sederhana yang mana setiap individu didalam populasi memiliki eluang yang setara dalam menjadi sampel tanpa megindahkan ciri khas yang dimiliki oleh individu tersebut (9). Adapun yang menjadi variabel dalam penelitian ini yaitu tingkat pengetahuan remaja laki-laki mengenai kesehatanr eproduksi. Tingkat pengetahuan remaja lakilaki dikategorikan menjadib aik dan kurang baik berdasarkan nilai median dikarenakan distribusi data dalam sampel penelitian ini tidak normal.

Instrumen yang digunakan dalam penelitian ini berupa kuesioner kesehatan reproduksi remaja yang dirancang oleh peneliti dengan hasil uji validitas $0,465-0,991$ dan hasil uji reliabilitas $0 .=, 965$ yang mana kuesioner tersebut diisi secara mandiri oleh responden. Kriteria inklusi pada penelitian adalah siswa laki-laki kelas 7 yang bersedia menjadi responden, disetujui oleh orang tuauntukberpartisipasi, sedang tidak menjalani opname di Rumah Sakit atau klinik dan bias mengisi kuesioner secara mandiri. Sementara kriteria eksklusi pada penelitian ini adalah siswa yang tidak bersedia atau tidak diizinkan orang tua untuk menjadi responden dan sedang menjalani opname di Rumah Sakit atau Klinik

Penelitian ini telah dilakukan pada tanggal 30 Juni s/d 21 Agustus Tahun 2020 dengan membagikan link google form kepada siswa. Data yang didapat di analisis menggunakanan analisis univariat dengan menampilkan distribusi frekuensi.

\section{HASIL DAN PEMBAHASAN}

\subsection{Hasil}

Dari 220 responden yang terlibat didalam penelitian ini, distribusi data mengenai tingkat pengetahuan remaja lakilaki mengenai kesehatan reproduksi yang secara rinci akan dijelaskan secara rinci dalam tabel dibawah ini.

Tabel 1. Karakteristik Responden $n=220$

\begin{tabular}{ccc}
\hline Pengetahuan & n & \% \\
\hline Baik & 123 & 55,9 \\
\hline Kurang & 97 & 44,1 \\
\hline Jumlah & $\mathbf{2 2 0}$ & $\mathbf{1 0 0}$ \\
\hline
\end{tabular}

Berdasarkan tabel 1 diatas, dapat dilihat bahwa lebih dari separuh respondenya itu sebanyak 123 responden $(55,9 \%)$ dengan tingkat pengetahuan baik.

\subsection{Pembahasan}

Sesuai dengan hasil penelitian ini menyatakan bahwa responden paling banyak dengan tingkat pengetahuan baik mengenai kesehatan reproduksi. Hal ini dikarenakan siswa laki-laki telah terpapar informasi dari 
berbagai sumber, media cetak, orang tua dan guru mengaji yang membahas mengenai kesehatan reproduksi sehingga mempengaruhi pola pikir dari siswa tersebut.

Hasil ini selaras terhadap penelitian terdahulu yang menunjukkan bahwa pengetahuan pada remaja di Desa Sidoharjo mengenai kesehatan reproduksi berada pada tingkat pengetahuan baik (10). Temuan ini juga serupa dengan penelitian yang telah dilakukan di Kota Palembang yang menyatakan bahwa pengetahuan remaja mengenai kesehatan reproduksi berada pada tingkat yang baik (11). Hal ini juga serupa dengan penelitian terdahulu yang dilakukan di SMA Negeri di Semarang yang menjelaskan bahwa tingkat pengetahuan remaja mengenai kesehatan reproduksi remaja berada pada tingkat yang baik (12).

Hal ini tidak sejalan dengan studi terdahulu di Desa Kertajaya Kabupaten Bandung Barat yang menunjukkan bahwa pengetahuan pada remaja mengenai kesehatan reproduksi berada pada tingkat pengetahuan yang sedang (13). Begitu pula dengan penelitian terdahulu yang dilakukan di SMK Wisnuwardhana Kota Malang yang menyatakan bahwa pengetahuan mengenai kesehatan reproduksi berada pada tingkat pengetahuan sedang (14). Sementara itu, penelitian yang dilakukan pada remaja siswa SMP di Yogyakarta yang membuktikan bahwa tingkat pengetahuan berdasarkan aspek tentang kesehatan reproduksi berada pada level sedang (15). Studi lain yang dilaksanakan di Kecamatan Buleleng menunjukkan bahwa pengetahuan remaja SMA/SMK mengenai kesehatan reproduksi berada pada tingkat yang sedang (16).

Remaja berada pada stase pertumbuhan dan perkembangan yang berlangsung cepat baik secara fisik, psikologis maupun intelektual (5). Berubahnya bentuk fisik yang cepat pada remaja, dimana kematangan seksual terjadi seiring dengan perkembangan seksualse cara primer dan sekunder. Perubahan primer yang berupa bentuk fisik dan system hormone yang menunjang reproduksi, dan perubahan sekunder yang terjadi padalaki-laki dan perempuan tentu tidak sama (17).

Pengetahuan mendasar mengenai kesehatan remaja pada bagian reproduksi yaitu pengenalan mengenai pengertian, proses, fungsi, dan sistem organ reproduksi. Pengetahuan dan persepsi yang kurang tepat mengenai perbedaan kelamin dan Kesehatan organ reproduksi dapat mengakibatkan remaja cenderung memiliki perilaku yang berisiko terhadap kesehatan organ reproduksinya sehingga sangat penting untuk melihat pengetahuan remaja tentang kesehatan reproduksi (3).

Pada organ reproduksi yang kebersihannya kurang terjaga akan sangat rentan terkena penyakit yang di akibatkan oleh jamur atau bakteri. Penyakit yang berkaitan dengan organ reproduksi juga dapat di akibatkan oleh pola hidup yang kurang sehat pada masa remaja, adalah salah satunya dengan kebiasaan merokok dan konsumsi alkohol sehingga dapat mengakibatkan impotensi. Penyakit tersebut juga tidak selalu timbul pada saat ini juga, namun bias beberapa tahun kedepan yang tentunya berpengaruh pada fertilitas laki-laki pada masa reproduksi, sehingga dibutuhkan pengetahuan yang baik (6).

Kurangnya pengetahuan pada remaja mengenai bagaimana proses reproduksi, pentingnya untuk menjaga kebersihan organ reproduksi, dan bagaimana dampak dari perilaku menyimpang sehingga menyebabkan sebagian dari remaja menjadi kurang menyadari tentang betapa perlunya untuk memelihara kesehatan organ reproduksi (8). Remaja perlu dibekali mengenai pengetahuan terkait dengan kesehatan reproduksi ehingga diharapkan mereka memiliki informasi yang jelas tentang bagaimana proses yang terjadi pada sistem reproduksi serta berbagaif aktor yang dapat mempengaruhinya (18).

Kesehatan reproduksi merupakan suatuk ondisi yang sehat, baik secara fisik, mental, dan sosial, namun tidak berarti bebas dari segala bentuk penyakit atau kecacatan yang berhubungan dengan sistem, fungsi, dan proses reproduksi (3).

Pemberian informasi mengenai perihal seksual menjadi penting untuk dilakukan karena pada masa remaja ada pada keadaan potensi seksual yang aktif dan berhubungan dengan dorongan fungsi seksual yang disebabkan oleh pengaruh hormon serta kurang terpapar dengan informasi yang memadai tentang aktifitas seksual. Hal tersebut akan memberikan dampak yang berbahaya bagi perkembangan psikologis 
pada remaja bila tidak disertai dengan adanya pemahaman yang benar dan informasi yang banar pula (19).

Berdasarkan pembahasan diatas, didapatkan bahwa remaja pada umumnya dan remaja laki-laki pada khususnya mempunyai pengetahuan yang baik, dimana pengetahuan yang baik mengenai kesehatan reproduksi akan dapat mempertahankan status kesehatannya dengan baik.

\section{KESIMPULAN}

Kesimpulan yang dapat diambail yaitu: di SMP 4, 6, dan 17 Kota Jambi mempunyai pengetahuan yang baik terhadap kesehatan reproduksi. Upaya yang dapat dilakukan oleh petugas Kesehatan di setiap Puskesmas yang membawahi tiap sekolah yang berada dalam wilayah kerja Puskesmas tersebut adalah dengan memberikan edukasi secara berkala bagi remaja mengenai kesehatan reproduksi yang baik, sehingga didapatkanp emahaman yang benar dan terhindar dari dampak buruk penyimpangan kesehatan reproduksi.

\section{REFERENCES}

1. Sarwono. 2011. Psikologi Remaja. Jakarta: Raja Grafindo Persada.

2. Badan Kependudukan dan Keluarga Berencana Nasional. 2011. Kajian Profil Penduduk Remaja (10-24 Tahun) : Ada Apa dengan Remaja. Jakarta: BKKBN.

3. Kementerian Kesehatan Republik Indonesia. 2018. Pentingnya Menjaga Kebersihan Alat Reproduksi. Jakarta Kemenkes RI.

4. Rosyida. 2019. Buku Ajar Kesehatan Reproduksi Remaja dan Wanita. Yogyakarta: Pustaka Baru Press.

5. Badan Kependudukan dan Keluarga Berencana Nasional. 2013. Survei Demografi dan Kesehatan Indonesia 2012 Kesehatan Reproduksi Remaja Laporan Pendahuluan. Jakarta: BKKBN.

6. Romauli, V. 2019. Kesehatan Reproduksi: Buat Mahasiswi Kebidanan. Yogyakarta: Nuha Medika.

7. Notoatmodjo, S. 2014. Promosi Kesehatan Dan Perilaku Kesehatan. Jakarta: Rineka Cipta.

8. Widyastuti. 2019. Kesehatan Reproduksi. Yogyakarta: Fitra Maya.
9. Dharma, KK. 2011. Metodologi Penelitian Keperawatan. Jakarta: Trans Info Media.

10. Ernawati, H. 2018. Pengetahuan Kesehatan Reproduksi Remaja Di Daerah Pedesaan. Indones J Heal Sci. 2(1):58.

11. Risa, Devita DU. 2017. Gambaran Media Informasi, Pengaruh Teman, Tempat Tinggal dengan Pengetahuan Kesehatan Reproduksi Remaja di Kota Palembang Tahun 2017. Lemb Penelitian, Pengemb Pembelajaran Pengabdi Kpd Masy. 1-8.

12. Masfiah, Siti., Zahroh Shaluhiyah AS. 2013. Pendidikan Kesehatan Reproduksi Remaja (PKRR) Dalam Kurikulum SMA Dan Pengetahuan \& Sikap Kesehatan Reproduksi Siswa. J Promosi Kesehat Indones. 8(1):69-78.

13. Irawan, E. 2016. Gambaran Pengetahuan Remaja Tentang Kesehatan Reproduksi Di Desa Kertajaya. J Keperawatan BSI. 4(1):26-31.

14. Kartikasari D, Ariwinanti D, Hapsari A. 2019. Gambaran Pengetahuan Kesehatan Reproduksi Siswa Smk Wisnuwardhana Kota Malang. J Prev. 4(1):36.

15. Indra Lukmana C, Ani Yuniarti F. 2017. Gambaran tingkat pengetahuan kesehatan reproduksi remaja pada siswa SMP di Yogyakarta. Indones J Nurs Pract. 1(3):115-23.

16. I Made Kusuma Wijaya, Ni Nyoman Mestri Agustini GDTM. 2014. Pengetahuan, Sikap Dan Aktivitas Remaja Sma Dalam Kesehatan Reproduksi Di Kecamatan Buleleng. $J$ Kesehat Masy. 10(1):33-42.

17. Potter and Perry. 2011. Fundamental of Nursing: Concept, Process and Practice. Edisi ke-7. Jakarta: EGC.

18. Efendi F, Makhfudi. 2013. Keperawatan Kesehatan Komunitas Teori dan Praktek dalam Keperawatan. Jakarta: Salemba Medika.

19. Kementerian Kesehatan Republik Indonesia. 2014. InfoDATIN. Situasi Dan Analisis HIV AIDS. Pusat Data dan Informasi Kementerian Kesehatan RI. Jakarta: Kemenkes RI. 